\title{
Escritura teatral. \\ Los ciegos: una tragedia simbolista
}

\author{
Mario Sánchez Vanegas \\ Recibido: 18 de junio del 2018 \\ Enviado a pares evaluadores: 28 de junio del 2018 \\ Aprobado por Comité editorial: 29 de junio del 2018 \\ https://doi.org/10.22395/csye.v7n13a6
}

\section{RESUMEN}

Los ciegos de Maurice Maeterlinck es la obra que expondré en este texto como una "tragedia griega". En términos dramáticos, presenta la languidez y el desfallecimiento existencial del hombre, el desamparo y la orfandad en que se halla ante un designio incognoscible y lóbrego. La argumentación se construye a través de la importancia que Nietzsche da al coro como un papel apolíneo para hacer explícito el sufrimiento. Así mismo, planteo que Maeterlinck no duda en hacer de esta pieza un gran coro que proclama la verdad del mundo y no otra sino "la de lo espantoso y absurdo del ser".

Palabras clave: Los ciegos; Maurice Maeterlinck; simbolismo; teatro estático; tragedia griega; Friedrich Nietzsche.

Maestro en Arte Dramático de la Universidad de Antioquia (Colombia) y Especialista en Dramaturgia de la Universidad Nacional de las Artes (Argentina). Trabaja como director general en el Teatro El Fractal y como director de teatro en la Universidad EAFIT (Colombia). Correo electrónico: teatrodetritus@gmail.com 


\section{Theatrical Writing. The Blind: A Symbolist Tragedy}

\section{ABSTRACT}

In the present text, I present The blind by Maurice Maeterlink as a "Greek tragedy". In dramatic terms, it presents the languor and existential faintness of men, the helplessness and orphanage in which he finds himself before an incomprehensible, depressive and dark design. Arguments are based on the importance that Nietzsche assigns to the choir, as an
Apollonian role to make suffering explicit. Likewise, I propose that Maeterlinck does not hesitate to make a great chorus of this piece that proclaims the truth of the world, one of "the frightful and absurd of being".

Keywords: The blind; Maurice Maeterlinck; symbolism; static theatre; greek tragedy; Friedrich Nietzsche.

\section{Escritura teatral. Os cegos: uma tragédia simbolista}

\section{RESUMO}

Os cegos, de Maurice Maeterlinck, é a obra que apresentarei neste texto como uma "tragédia grega". Em termos dramáticos, apresenta a languidez e o desfalecimento existencial do homem, o desamparo e a orfandade em que se encontra diante de um desígnio incognoscível e lúgubre. A argumentação se constrói através da importância que Nietzsche dá ao coro como um papel apolíneo para explicitar o sofrimento. Igualmente, proponho que Maeterlinck não duvida ao fazer dessa peça um grande coro que proclama a verdade do mundo e não outra diferente da "do espantoso e absurdo do ser".

Palavras-chave: Os cegos; Maurice Maeterlinck; simbolismo; teatro estático; tragédia grega; Friedrich Nietzsche. 
La tragedia está muy bien ordenada. Todo es seguro y tranquilizador. En el drama, con todos esos traidores, esos malvados fanáticos, esa perseguida inocencia, ese fulgor de esperanza, es horrible morir, como un accidente [...] En la tragedia puede uno estar tranquilo [...] Después de todo, en el fondo, todos son inocentes. No porque uno mate y el otro sea muerto, es sólo [sic] cuestión del reparto de papeles. Y además, la tragedia es sobre todo tranquilizadora, porque desde el principio se sabe que no hay esperanza, esa sucia esperanza [...] En el drama se lucha, porque se espera en cierto modo poder salvarse. Es repugnante. Eso tiene un sentido. Pero aquí todo es absurdo. Todo es vano. Finalmente, ya no hay que intentar nada.

Antígona de Jean Anouilh, citado por Albin Lesky en La tragedia griega (2001)

Los dramas de Maeterlinck son sobre todo una epifanía, una purificación de las almas. Sus dramas son un coro de almas que cantan a media voz el sufrimiento, el amor, la belleza y la muerte. Hay en ellos una simplicidad que transporta lejos de la tierra, un goce estático o una armonía que anuncia el reposo.

Vsevolod Meyerhold en Teoría teatral: historia y técnica del teatro (2013)

[...] la ceguera también es esto, vivir en un mundo donde se ha acabado la esperanza.

José Saramago en Ensayo sobre la ceguera (1999)

\section{Introducción}

¿Cómo puede un teatro que prescinde de la acción y la mímesis estar tan cerca de la tragedia griega? Es una propuesta que podríamos decir que pertenece a la "vanguardia hermética", desarrollada como una estética de la provocación a mitad del siglo XX, su principal apoderado es el teatro de los simbolistas y en este, Maurice Maeterlinck con su obra Los ciegos, un manifiesto que él denomina drame statique (drama estático) y de esta manera rechaza la idea clásica de un tiempo inexorable que avanza hacia adelante y de modo lineal, en beneficio de una imagen-tiempo plana (Lehmann, 2013).

Sin mucho esfuerzo, podríamos decir que La Isla de los Muertos (1880) de Arnold Böcklin (1827-1901), inicial y paradójicamente llamada Un lugar tranquilo, es el espacio ideal para Los ciegos (1890), obra escrita por Maurice Maeterlinck 
(1862-1949) que junto con La intrusa (1890), Las siete princesas (1891) y Pelleás y Mélisande (1892), integran la serie "teatro estático" como una nueva forma de ver y representar el teatro buscando otras formas de expresión. En palabras del autor:

Hay en la vida cotidiana algo de trágico, mucho más real, mucho más profundo y mucho más conforme con nuestro ser verdadero que lo trágico de las grandes aventuras. Es fácil de sentir, pero difícil de mostrar, porque esa tragedia esencial no es simplemente material o psicológica. Ya no se trata aquí de la lucha determinada de un ser contra un ser, de la lucha de un deseo contra otro deseo o del eterno combate de la pasión y del deber. Se trataría más bien de hacer ver lo que hay de sorprendente en el solo hecho de vivir. (Maeterlinck, M. (2003) La tragedia cotidiana. Gaceta, universidad veracruzana,(67-69) Recuperado de https://bit.ly/2TbElbF)

La obra de Böcklin constituye uno de los trazos profundos del movimiento simbolista en el momento en el que los poetas buscaban una reivindicación en contra de los valores del materialismo y el pragmatismo, como reacción al naturalismo y al realismo, mediante narraciones opuestas a la realidad visible, es el sueño frente a la razón, más allá del divertimento y la sustantividad informada. Es lo que Jean Moréas define en el manifiesto literario publicado en 1886 como "enemigo de la enseñanza, la declamación, la falsa sensibilidad y la descripción objetiva" (Schmidt, 1960). De esta forma, parecía incontenible el surgimiento de un teatro en el que el ser humano se enfrenta con su peor tragedia: su propia realidad existencial.

Baudelaire y Flaubert, los que más insistieron en tan ardua campaña de esta modalidad de escritura para teatro, fracasaron en su tarea dramatúrgica. Despertaron así en el pensamiento estético de la época, la necesidad de una dramática que exigía que fuera un dramaturgo de oficio el que provocara una colisión estética y final contra el naturalismo. Es entonces cuando Maeterlinck con su obra Los ciegos, abre el camino para el teatro hacia ese universo oscuro y enigmático gracias al uso audaz de metáforas que buscaban evocar las afinidades ocultas por medio de la sinestesia, como en su momento lo definieron Stéphane Mallarmé (1842-1898) y Paul Verlaine (1844-1896), precursores del movimiento en la década de 1870.

Maeterlinck inicia un teatro que "no es en los actos, sino en las palabras, donde se encuentran la belleza y la grandeza de las bellas y grandes tragedias." (Maeterlinck, 2003)

Es así que el "teatro estático" en tanto tragedia no depende de las acciones de los personajes ni de la posible interacción entre ellos, sino de lo que sus palabras ponen en evidencia. En este sentido, Jorge Dubatti, por ejemplo, en su ensayo "Maurice Maeterlinck y el drama simbolista" (en el Centenario del estreno mundial de "El Pájaro Azul", 2009) afirma que a la obra de Maeterlinck 
la caracteriza con precisión esa búsqueda y revelación de los misterios de la vida a través de las palabras:

Maeterlinck reclama al espectador una disponibilidad espiritual hacia lo sagrado, el Misterio, el Enigma en tanto indescifrable pero no por eso menos perceptible como sentimiento y experiencia. Invita además al reconocimiento del arte desde su autonomía y soberanía, y a encontrar en éste [sic] una consecuente instrumentalidad espiritual. (Dubatti, 2009)

Al abordar este movimiento del "teatro estático" no se puede dejar de hacer mención a otros de sus representantes: Fernando Pessoa (1888-1935), con El Marinero (1933), que su autor define como "drama estático en un cuadro"; encaminado hacia la "tragedia de un teatro simbolista" con obras como Yerma (1934), La casa de Bernarda Alba (1936) y Bodas de sangre (1933), el poeta y dramaturgo Federico García Lorca (1898-1936), evidencia el simbolismo como instrumento de creación y lenguaje trágicos, por ejemplo, en Así que pasen cinco años (1931) y en el dibujo "invisible" de la muerte en la escena final de Doña Rosita la soltera (1935) mediante efectos sonoros, cambios de luz, etc., inspirados en La Intrusa de Maeterlinck, a quien mencionó en una ocasión -cosa que no solía hacer-con dos adjetivos concluyentes: "enorme y admirable". (Impresiones y paisajes, Federico García Lorca, 1998). Sin embargo, este "teatro estático" no es nuevo o así lo expone Meyerhold:

Las mejores tragedias antiguas, Las Euménides, Antígona, Electra, Edipo en Colonna, son estáticas, carecen no sólo [sic] del llamado "argumento", sino incluso de acción psicológica. Las tragedias antiguas constituyen ejemplos de teatro inmóvil, en los que la fuerza trágica está representada por el destino y por la posición del hombre en el universo [...] Es necesario un teatro inmóvil también en el plano técnico, un teatro que considere el movimiento como música plástica, como expresión exterior de una emoción interior (movimiento entendido como ilustración). La técnica del teatro inmóvil prefiere por esto gestos contenidos y movimientos limitados; teme los movimientos superfluos porque distraen al espectador de los complejos sentimientos interiores que pueden captarse únicamente en un rumor, en una pausa, en el temblor de una voz, en una lágrima que vela los ojos del actor. (Meyerhold, 2013, p. 159)

¿Cómo sucede la tragedia en Los ciegos de Maeterlinck? Sabemos que Friedrich Nietzsche (1844-1900) al momento de escribir El nacimiento de la tragedia en el espíritu de la música (1872) era un gran admirador de Arthur Schopenhauer (1788-1860) y fue la obra El mundo como voluntad y representación (1819) de este autor la que en principio orientó de alguna forma la obra nietzscheana en consideraciones sobre la naturaleza y el sentido de la tragedia como que:

El placer que la tragedia nos proporciona no pertenece al sentimiento de lo bello, sino al de lo sublime. Una escena sublime de la naturaleza que se desarrolla ante nosotros, muchas veces nos produce el efecto de anular la voluntad para mantenernos 
en disposición puramente contemplativa; pues, de igual modo, ante la catástrofe trágica nos desprendemos hasta de la misma voluntad de vivir. El campo de acción de la tragedia es el aspecto aterrador de la vida, ofreciéndonos el espectáculo de la miseria humana, el reinado del error y del azar, la pérdida del justo, el triunfo de los malvados; contemplamos, pues, todo aquello que más repugna a nuestra voluntad en el sistema del mundo. Este espectáculo nos conduce a apartar la voluntad de la vida, a no amar a ésta [sic] ni a desearla. (Schopenhauer, 1960)

La anterior descripción sobre la tragedia calzaría como un guante a Los ciegos de Maeterlinck, dado que la propuesta del dramaturgo simbolista es un despliegue sobre la conciencia trágica ante los horrores en los que se resuelve la existencia fútil al tratar de penetrar en la artificialidad de los deseos, en los caprichos de las pasiones y en la exquisitez de la voluntad de vivir.

Del mismo modo, y siendo el concepto nietzscheano sobre la tragedia el que aquí me interesa, el Coro es lo que mejor calza a la obra de Maeterlinck. Lo anterior después de que Nietzsche realizara una casi irrefutable diferenciación entre lo apolíneo y lo dionisíaco, concebidos como dos componentes fundamentales por su oposición y complementación simultánea con el espíritu griego -dos realidades que Schopenhauer habría llamado "representación" y "voluntad" -.

Asimismo, después de que Nietzsche estableciera un dios de la mitología griega como personificación de cada componente así: lo dionisíaco de Dioniso, que según Nietzsche es un dios que sufre pero, a la vez, exaltadamente jubiloso: el dios del vino y de la embriaguez. El dios que bendecía la identificación entusiasta de todos los miembros de la comunidad durante la apoteosis de la orgía. Deidad que combina, según la descripción nietzscheana, la más despiadada crueldad con la más amable benevolencia, el ímpetu salvaje con la clemencia y la benignidad.

Lo apolíneo de Apolo encarna las fuerzas opuestas, es-de acuerdo con la tradición griega que Nietzsche interpreta- el dios resplandeciente, es decir, la divinidad de la luz, el dios de las artes figurativas que preside el mundo de la representación, de la fantasía y "la bella apariencia de lo onírico". Es también, como Nietzsche subraya, el dios vaticinador, el intérprete de los sueños y del destino.

Frente a Dioniso, que patrocina la fusión orgiástica de los espíritus, Apolo simboliza más bien el principio de individualización. Ambos principios tuvieron en el origen, según Nietzsche reconoce, su cauce propio: lo dionisíaco en las exaltadas festividades orgiásticas en las que todo desenfreno estaba permitido y se buscaba la compenetración mística de los protagonistas de la fiesta, asumiendo así el "desgarramiento del principium individuationis" como un fenómeno artístico; lo apolíneo, en las artes representativas, es decir, en la pintura y escultura o, también, en la poesía épica (Nietzsche, 1977). 
Después de esta diferenciación que describe en varios apartes de su obra como "un coro dionisíaco que se descarga en un mundo apolíneo de imágenes", o bien como "una representación simbólica de la sabiduría dionisíaca por medios artísticos apolíneos" o finalmente, como una "visión que es en su totalidad una apariencia onírica y por tanto de naturaleza épica, más, por otro lado es objetivación de un estado dionisíaco", afirma Nietzsche que la tragedia, originariamente, fue "coro y nada más que coro: de lo cual sacamos nosotros la obligación de penetrar con la mirada hasta el corazón de ese coro trágico, que es el auténtico drama primordial".

Así como Nietzsche da al coro el papel apolíneo de hacer explícito el sufrimiento, de igual manera Maeterlinck no duda en hacer de esta pieza un gran coro que proclama la verdad del mundo y no otra sino "la de lo espantoso y absurdo del ser", un gran coro compuesto por doce ciegos (seis hombres y seis mujeres, una de ellas con un niñito en brazos) que esperan a ser regresados a su refugio guiados por el sacerdote que yace muerto entre ellos, "en medio, hacia el fondo de la noche, sentado, muy anciano, envuelto en una capa". Seis mujeres a la izquierda y, separados por un árbol descuajado y pedazos de roca, seis hombres a la derecha, ubicados diametralmente a los lados de quien sería su única salvación, el cadáver del sacerdote. Lo anterior inevitablemente evoca la Última Cena de Jesús y los doce apóstoles, solo que en esta ocasión hablaríamos de un Jesús muerto rodeado por sus discípulos, que al reconocerlo muerto y muerta su única salvación, desesperan pidiendo misericordia, a lo que solo les responde el silencio rasgado por leves sonidos de pasos que muelen las hojas y el viento. El niño, el único que puede ver, pero no hablar, parece ser testigo de aquella presencia que los demás no pueden descifrar y que Maeterlinck, haciendo uso del simbolismo como plástica ligada al diálogo, limita la situación a la palabra explicitando el elemento esencial y decisivo de la tragedia: lo irremediable.

En concordancia con Nietzsche con respecto a que el coro constituye el elemento fundamental de la tragedia, hay tres tipos de voces que pueden ser relevantes en el coro. Una primera cuando por medio del coro habla la polis, el ciudadano medio, con el cual todos o casi todos se identifican y que va comentando los episodios de la tragedia, hablando como si fuera el sentido común, expresando los temores ancestrales, las expectativas recónditas que los protagonistas comparten, pero que no hacen explícito para no comprometer sus ideales.

Una segunda voz del coro es la de la tradición, origen y fundamento de las instituciones y la mentalidad de la polis. Mientras los ciudadanos del común son construcciones socio-culturales, el héroe gesta su condición heroica a través de la transgresión de las instituciones y las normas vigentes. De allí que la 
tradición interpele al héroe casi que "maternalmente" a través del coro, cuando lo invita a la prudencia, no sea que suscite la envidia de los dioses o la ira de las erinias; y finalmente, una tercera voz que habla de la sabiduría poética, esa que Esquilo y Sófocles -profundos conocedores de la sociedad de su tiempo, de las tradiciones, pero también de los anhelos, vicisitudes y conflictos del hombre griego-terminan por formular. Del mismo modo, Los ciegos como coro es apenas un grupo de individuos, con personajes sin nombres propios, sin jerarquización alguna de protagonismo, invidentes todos, también unificados por el color y el estilo de sus ropajes -que fácilmente nos convoca a el "quitón", una especie de túnica interior larga hasta los pies, ceñido por un cinturón, la "clámide", una capa corta, y el "himatión"-, que eran semejantes a una capa larga, que Maeterlinck decribe como "vestiduras amplias, sombrías y uniformes", haciendo abstracción material de sus cuerpos, aligerando su pesadez, y conectando de alguna forma su individualidad y psicología en el orden de la trascendencia.

¿Puede ser legítimo hablar de "tragedia" cuando hablamos de Los ciegos? Si se tiene en cuenta la situación trágica en la que están inmersos los personajes de la obra, cuyo tema es un conflicto absolutamente trágico con un final fúnebre, sí se legítima dicho postulado.

Bastaría, acaso, hacer alusión a lo irremediable como elemento esencial y decisivo de lo trágico, esto con base en la distinción conceptual que Lesky formula en El problema de lo trágico cuando expone que es "en las fuerzas opuestas que se levantan unas contra otras, donde está el ser humano que no encuentra la solución a su conflicto y ve su existencia entregada a la destrucción" . Comencemos por exponer por qué la visión radicalmente trágica del mundo expuesta en Los ciegos cumple con la destrucción incondicional de fuerzas y valores, sin solución y que no puede explicarse con ningún sentido trascendente:

EL CIEGO MÁS VIEJO: No nos hemos visto nunca unos a otros. Nos preguntamos y nos respondemos; vivimos juntos, estamos siempre juntos, pero no sabemos lo que somos... Por mucho que nos toquemos con las dos manos... los ojos saben más que las manos

Como segundo punto, Lesky, traza y designa el conflicto trágico absoluto como aquel al que se refería Goethe cuando hablaba de lo trágico, un conflicto que, por muy absoluto que fuera en sí mismo no representaría al mundo por entero, por lo que resulta concebible que tenga que finalizar con la muerte y la destrucción:

LA CIEGA MÁS VIEJA: No sabíamos nada... No le hemos visto nunca... ¿Cuándo hemos sabido algo bajo nuestros pobres ojos muertos?... No se quejaba... Ahora es demasiado tarde... iHe visto morir a tres, pero así, nunca! Ahora nos toca a nosotros... 
Y como tercer fenómeno, Lesky separa de los anteriores a la situación trágica, en la que se levantan las fuerzas opuestas unas contra otras, el ser humano no encuentra solución a su conflicto y ve su existencia entregada a la destrucción, excepto que en Los ciegos -a diferencia de lo que plantea Lesky al final de esta acepción- la situación trágica se experimenta dolorosamente con todo su peso y es definitiva.

En medio, hacia el fondo de la noche, está sentado un Sacerdote muy anciano, envuelto en ancha capa negra. El busto y la cabeza ligeramente inclinados y mortalmente inmóviles, se apoyan contra el tronco de una encina enorme y cavernosa. El rostro es de inmutable lividez de cera, y en él se entreabren los labios violeta. Los ojos, mudos y fijos, no miran ya del lado visible de la eternidad [...]

Es así como nos podemos volver a encontrar con el texto de Nietzsche cuando describe el arte como

[...] un mago que salva y cura; únicamente él es capaz de retorcer esos pensamientos de náusea sobre lo espantoso y lo absurdo de la existencia, convirtiéndolos en representaciones con las que se puede vivir: esas representaciones son lo sublime, sometimiento artístico de lo espantoso, y lo cómico, descarga artística de la náusea de lo absurdo. (Nietzsche, 1977)

Descubre así del lenguaje trágico el "producto de una mirada que penetra en lo íntimo y horroroso (en lo dionisíaco y sufriente) de la naturaleza" (Nietzsche, 1977).

Los ciegos junto al acantilado de una isla rodeada por el mar son tan vulnerables como aquel hombre que Nietzsche cita de Schopenhauer:

Como un pescador en una barca, tranquilo y lleno de confianza en su frágil embarcación, en medio de un mar desencadenado, que, sin límites y sin obstáculos, eleva y abate, mugiendo, montañas de olas espumosas, el hombre individuo, en medio de dolores, permanece impasible y sereno, apoyado con confianza en el principium individuationis. (Nietzsche, 1977)

Ahora, supongamos que esa duda que por un segundo llega a sospechar el hombre de la balsa sobre aquella calma aparente, sobre una verdad más real e intensa, es la verdad que abrazó a los ciegos en aquel lugar lejos de su refugio y que apenas se atreven a confrontar para descubrir, en un mundo de aparente calma y equilibrio, que el caos llega de la mano de la muerte, lo que los convierte en animales que provocan lástima. Entran así como aquel hombre, en un estado dionisíaco de perturbación extraordinaria ante las potencias titánicas de la naturaleza que los rodea y de su propia naturaleza: ciegos, algunos de nacimiento, y viejos, sin la menor esperanza de recuperar el equilibrio inicial, víctimas de su propia condición humana. Por ello no cabría duda de que la verdad de Sileno sería tan reveladora en esta situación como lo fue en Nietzsche: "lo que debes 
preferir es no haber nacido, no ser, ser nada. Y además lo que mejor puedes anhelar es... morir pronto" (Nietzsche, 1977).

PRIMER CIEGO DE NACIMIENTO: iHay un muerto entre nosotros, os digo! iOh! iOh! iHe tocado la cara de un muerto! iEstáis sentados junto a un muerto! iEstáis sentados junto a un muerto! iSin duda, uno de nosotros [h] a muerto de repente! iPero hablad, que yo sepa quiénes son los que viven! ¿Dónde estáis? iResponded! iResponded todos a la vez! (Los ciegos responden sucesivamente, excepto la Ciega loca y el Ciego sordo; las Tres viejas han dejado de rezar). Ya no distingo vuestras voces!... ¿Habláis todos lo mismo? iTodos tiemblan!"

Caronte de pie, abrigado por un sudario y acompañado solo por lo que parece un ataúd, desliza sobre la superficie inmutable su barca hacia las entrañas de una isla rocosa, su morada, el inframundo. Ya no alcanzamos a ver más que ese pequeño bosque de cipreses del que probablemente, solo se escuchen los lamentos despedazados a gritos de los ciegos, allí, desahuciados.

\section{Conclusión}

En conclusión, Maeterlinck realiza la primera dramaturgia antiaristotélica de la Modernidad, el primer acometido de lo que llamamos teatro estático; es el mejor ejemplo de lo que suscita la eclosión entre los teóricos de la literatura dramática, dado que desde Aristóteles no había surgido una propuesta que suprimiera toda dialéctica entre la forma y el contenido, que rescindiera el quid de la definición aristotélica del teatro: la acción.

En palabras de Peter Szondi:

Si la tragedia griega había mostrado al protagonista en trágica pugna con el destino o el drama del Clasicismo indaga[n]do los conflictos latentes en la relación interpersonal, aquí se tratará exclusivamente de captar el momento en que el hombre se ve sorprendido en su indefensión por el destino.

\section{Referencias}

Dubatti, J. (2009). Concepciones de teatro. Poéticas teatrales y bases epistemológicas. Buenos Aires: Colihue.

García Lorca, F. (1998). Impresiones y paisajes. Madrid. España: Colección Cátedra. Letras Hispánicas.

Gombrich, E. H. (2006). The Essential Gombrich. Tailandia: Ed. Phaidon.

Lehmann, H. T. (2013). Teatro Posdramático. México: Cendeac.

Lesky, A. (2001). La tragedia griega. España: Ed. Acantilado.

Maeterlinck, M. (2003) La tragedia cotidiana. Gaceta, universidad veracruzana (67-69). Recuperado de https://bit.ly/2TbElbF

- 142 
Maeterlinck, M. (2009). La intrusa, Los ciegos, Pelleas y Melisande, El pájaro azul. Madrid: Ed. Cátedra. Meyerhold, V. (2013). Teoría teatral: historia y técnica del teatro. Madrid: Ed. Fundamentos.

Nietzsche, F. (1977). El nacimiento de la tragedia (A. Sánchez Pascual, trad.). Madrid: Alianza.

Saramago, J. (1999). Ensayo sobre la ceguera. Madrid: Ediciones Alfaguara.

Schmidt, A M. (1960). La Literatura simbolista. Buenos Aires: Eudeba.

Schopenhauer, A. (1960). El mundo como voluntad y representación, vol. II. Madrid-Buenos Aires-México: Ed. Fondo Cultura Económica.

Szondi, P. (2011). Teoría del drama moderno (1880-1950) Tentativa sobre lo trágico. Madrid: Clásicos Dykinson. 